\title{
O PROCESSO ENSINO-APRENDIZAGEM EM ADMINISTRAÇÃO EM CONDIÇÕES DE HETEROGENEIDADE: PERCEPÇÃO DE DOCENTES E DISCENTES
}

\author{
THE TEACHING-LEARNING PROCESS FOR \\ ADMINISTRATION CLASSES IN HETEROGENEOUS CONDITIONS: \\ STUDENTS' AND TEACHERS' PERCEPTIONS
}

Recebido em: 03/12/2010 Aprovado em: 29/11/2011 Avaliado pelo sistema double blind review

Editora Científica: Manolita Correia Lima

\author{
KÁTIASANTOS DE MORAIS \\ UNIVERSIDADE DO ESTADO DA BAHIA
}

INGRID WINKLER

ingridw@uol.com.br

UNIVERSIDADE FEDERAL DA BAHIA

\section{JÚLIO CESAR ANDRADE DE ABREU UNIVERSIDADE FEDERAL FLUMINENSE}

\author{
LINDOMAR PINTO DA SILVA \\ FACULDADE ANÍSIO TEIXEIRA \\ JOSÉ ANTONIO GOMES DE PINHO
UNIVERSIDADE FEDERAL DA BAHIA
}

RESUMO

O objetivo do trabalho é descrever uma experiência de ensino baseada no olhar discente e docente em um projeto experimental da disciplina "Introdução à Administração", ministrada para alunos de cursos como Engenharia, Nutrição, Direito, constituindo-se numa turma, portanto, heterogênea em sua formação. A dinâmica da disciplina é marcada pela realização de aulas-conferência, proferidas pelo professor, e aulas em microgrupos, coordenadas individualmente pelos monitores, funcionando como um processo simultâneo e complementar, a fim de possibilitar espaços mais amplos para a troca de experiências. A discussão adotou como referencial teórico os conceitos de aprendizagem significativa e interação (MOREIRA, I999; AUSUBEL, I982) e o uso de recursos estéticos para favorecimento da aprendizagem (DAVEL et al., 2004; FISCHER, 2005). Valendo-se de uma pesquisa survey, o artigo analisa, quantitativa e qualitativamente, a percepção de alunos e docentes sobre o formato da experiência. Conclui-se que a heterogeneidade dos cursos de origem dos estudantes constitui um grande desafio, mas possibilita também diversas oportunidades de uma aprendizagem significativa. Este formato pode, então, servir de base para novos experimentos e colaborar com reflexões sobre a necessidade de reformulação do ensino em Administração e da própria formação de docentes em Administração, como defendem alguns autores.

Palavras-chave: processo ensino-aprendizagem; aprendizagem significativa; ensino de administração.

\section{ABSTRACT}

The main goal of this article is to describe, from the points of view of teachers and students, a teaching experience from the "Introduction to Administration" class attended by a heterogeneous group of students from Engineering, Nutrition, Law and other courses. The class structure comprises lectures and small group based lessons coordinated by monitors that complement the lecture content in an encouraging environment for dialogue and exchanging experiences. The article adopts the concepts of meaningful learning and interaction (MOREIRA, 1999; AUSUBEL, 1982) as a theoretical framework and the use of aesthetic resources to improve learning (DAVEL et al., 2004; FISCHER, 2005). A survey was conducted and the resulting data quantitatively and qualitatively analyzed to gauge the students' and teachers' perception of the class. It was observed that the students' mixed course background posed a significant challenge, but also offered several important learning opportunities. This teaching format can, therefore, serve as a basis for new experiments and help to reflect on the need to re-structure the teaching process for Administration and the training of lecturers in the field, as suggested by some authors.

Keywords: teaching-learning process; meaningful learning; administration teaching. 


\section{INTRODUÇÃO}

O objetivo deste trabalho é descrever uma experiência de ensinoaprendizagem com base em um formato de monitoria de ensino desenvolvido em uma turma da disciplina "Introdução à Administração", ministrada para alunos de diversos cursos que não Administração, a saber, Engenharias, Arquivologia, Direito, Nutrição, Ciência da Computação e Estatística. Constitui-se, desta forma, uma turma heterogênea em sua própria origem, convivendo em um mesmo ambiente de ensino.

O artigo, assim, discute a questão ensino-aprendizagem do ponto de vista dos instrumentos de ensino, na turma de 2008.2, da disciplina "Introdução à Administração" em uma universidade federal, situada na região Nordeste do país. Como a turma era formada por ing alunos, dada a sua quantidade e a já assinalada a heterogeneidade, optou-se pelo uso de um processo de ensino que visa aprimorar as condições para a aprendizagem. As aulas eram realizadas duas vezes por semana: o primeiro encontro era ministrado pelo professor responsável pela disciplina numa aula-conferência para toda a turma, enquanto, no segundo encontro, a turma era dividida em quatro grupos menores de 30 alunos e as atividades eram conduzidas por monitores, alunos de Mestrado e Doutorado do Programa de Pós-Graduação daquela Universidade. Os assuntos eram expostos e discutidos pelo professor no primeiro encontro em aulas expositivas, num foco mais teórico, e, no encontro seguinte, rediscutidos pelos monitores numa abordagem mais prática e interativa, com um foco mais aplicado, utilizando para isso outros recursos didáticos além das aulas expositivas, como estudos de casos, filmes e dinâmicas, por exemplo. O objetivo deste formato era propiciar condições para estimular o processo de aprendizagem significativa, dadas as condições acima descritas. Para Ausubel (1982), a aprendizagem torna significativa quando os novos conteúdos transmitidos são incorporados às estruturas de conhecimentos prévios dos alunos. Deste modo, o conhecimento deixa de ser uma associação arbitrária à estrutura cognitiva - processo chamado por Ausubel (1982) de aprendizagem mecânica - do aluno e passa a ser um 
processo que adquire sentido e significado.

Com base na formulação da teoria da aprendizagem significativa de Ausubel (1982), Pelizzari et al. (2002) afirmam que existem duas condições básicas para que ela aconteça: a primeira é que deve existir a vontade de aprender, por parte dos alunos; e a segunda é que o conteúdo a ser aprendido seja potencialmente significativo. Nesse sentido, um dos objetivos da organização do processo de ensino em aulas-conferências e aulas em microgrupos é propiciar condições para o debate dos conteúdos baseados na realidade de cada aluno, ou seja, o conhecimento prévio trazido por cada um, potencializando assim, os sentidos e significados dos temas abordados nas aulas-conferências.

Fundamentada nessa experiência advinda de uma numa proposta de aprendizagem significativa e na dinamicidade na interação entre professor e aluno, o artigo investiga a percepção dos alunos em relação a esse formato de ensino, bem como a visão dos docentes envolvidos em relação a tal experiência didática. Sendo assim, quanto aos objetivos, o artigo caracterizase como descritivo que, segundo Gil (2002), tem como objetivo primordial a descrição das características de determinadas populações ou fenômenos, como pesquisas que visam descrever características de grupos ou processos ou levantar as percepções de uma população. Nesse sentido, baseado na descrição da experiência - no relato dos docentes e na avaliação feita pelos alunos- o artigo busca levantar elementos que venham a contribuir para a reflexão sobre os benefícios e problemas do referido formato de ensino como parte do processo de construção da prática docente em Administração.

Destarte, o trabalho encontra-se organizado da seguinte forma: inicialmente é tecido um referencial teórico sobre processos de ensino aprendizagem; na segunda parte a experiência é detalhadamente descrita (procedimentos, conteúdos, etc.); segue-se com a apresentação da metodologia da pesquisa, que foi conduzida para captar a percepção tanto dos discentes como do docente e dos monitores envolvidos com a experiência. 


\section{O PROCESSO DE ENSINO-APRENDIZAGEM}

O Processo de ensino-aprendizagem compreende um conjunto de ações que envolvem pessoas, técnicas e instrumentos cujo objetivo é a construção de conhecimento para os indivíduos que não o dominam. Trata-se, assim, de construção e não de mera transferência de conhecimentos para uma plateia ávida por informações. Não se trata de um grupo de pessoas sentadas, predispostas a ouvir, enquanto há outro indivíduo supostamente iluminado, provido de saber, com a tarefa de repassar as informações para atender as expectativas daqueles indivíduos.

Pensar o processo de ensino-aprendizagem exige, portanto, reconhecer que os indivíduos não são repositórios de informações, a exemplo do que pensou Freire (1987), ao questionar o que qualificou como ensino bancário, por meio do qual um indivíduo "deposita” seus conhecimentos na cabeça de outros. Desta forma, pensar no processo de ensino-aprendizagem exige ultrapassar também a ideia de uma aprendizagem baseada no conceito de estímulo, resposta e reforços. É preciso, inclusive, avançar na ideia de um processo construído sob a égide da aprendizagem significativa, mudança conceitual e construtivismo (MOREIRA, I999). Tal concepção pressupõe que a aprendizagem significativa deve avançar para além das bases que pensavam que este processo fosse estático e centrado na figura do professor.

Moran (2008) afirma, em uma entrevista, que a aprendizagem significativa deve ser entendida como:

Partindo de situações concretas, de histórias, cases, vídeos, jogos, pesquisa, práticas e ir incorporando informações, reflexões, teoria a partir do concreto. (...) Não podemos dar tudo pronto no processo de ensino e aprendizagem. Aprender exige envolver-se, pesquisar, ir atrás, produzir novas sínteses fruto de descobertas. O modelo de passar conteúdo e cobrar sua devolução é ridículo. Com tanta informação disponível, o importante para o educador é encontrar a ponte motivadora para que o aluno desperte e saia do estado passivo, de espectador.

É oportuno destacar que ensino e aprendizagem (dois termos comumente empregados como sinônimos) são conceitos distintos. Para Leopoldino, 
Abreu e Santana (2008), enquanto o ensino está voltado para o trabalho do professor na busca da transmissão de conhecimentos, o conceito de aprendizagem relaciona-se mais ao processo de assimilação de conhecimentos por parte daquele que aprende, o que pode vir a ocorrer independentemente de qualquer processo de ensino. O ensino deve, obviamente, facilitar a aprendizagem, mas não existe necessariamente uma relação direta entre ambos. Um mesmo professor pode lecionar um conteúdo em uma turma e este processo de ensino gerar aprendizagem para alguns alunos e para outros não. Da mesma forma, alguns alunos podem desenvolver a aprendizagem fora de um contexto de ensino ou diante de um processo realizado inadequadamente. Telles, (1983) apud уолемото (2004, p. 55) corrobora esta visão:

Numa sala existe ensino, que é algo diferente de aprender. Ensino é a transmissão ou apresentação de certas orientações por parte de alguém, no caso, um professor, que facilita a aprendizagem por parte do aluno. O ensino, no entanto, ajuda a aprender.

Não há consenso na literatura sobre como se dá a aprendizagem (TONET; PAZ, 2006; YONEMOTO, 2004). São conhecidas várias abordagens teóricas que buscam explicar como ocorrem os processos de ensino e aprendizagem, muitas vezes com visões conflitantes. Destacam-se no conjunto de trabalhos as correntes de cunho construtivista e cognitivista, a corrente da aprendizagem significativa de Ausubel (1982) e os modelos dos comportamentalistas (AZENHA, 2006; BASTOS, 2004; MOREIRA, 1999). Estas contribuições teóricas enriqueceram o quadro da aprendizagem individual, embora estejam ainda distantes de encerrar as discussões nesta seara (LEOPOLDINO; ABREU; SANTANTA, 2008).

Como concepção teórica, a aprendizagem já foi compreendida mais como resultado e menos como processo. Esta visão despreza a importância do processo como um todo, que é fundamental para o próprio resultado. Weick e Westley (2004, p.363), discutindo a fragilidade de pensar apenas no resultado, descrevem:

Aprender enfatiza um verbo de realização. Isso significa que a palavra aprendizagem refere-se tanto a um resultado, quanto a um processo, possui 
sentido circular, tautológico e obscuro, em vez de revelar a dinâmica do processo e a natureza exata do resultado.

Ainda para reforçar dois importantes conceitos já mencionados neste texto, faz-se necessário detalhar o conceito de "aprendizagem significativa". Termo cunhado por Ausubel (1982), mas aprimorado por Joseph Novak (MOREIRA, I999, p.II), para quem a aprendizagem

[...] é um processo por meio do qual uma nova informação se relaciona de maneira substantiva (não literal) e não arbitrária, a um aspecto relevante da estrutura cognitiva do indivíduo. Isto é, nesse processo a nova informação interage com uma estrutura de conhecimento específica, a qual Ausubel chama de conceito subsunçor ou, simplesmente subsunçor, existente na estrutura cognitiva de quem aprende.

Assim, do conceito de Ausubel (1982) e de Weick e Westley (2004) fica clara a necessidade de interação do indivíduo, uma vez que sendo processo exige a interação, e sendo significativa exige a participação do aprendiz com prévios conhecimentos (subsunçores) para que o processo possa ser realizado e o aprendizado alcançado. Nas palavras de Moreira (I999), a aprendizagem significativa caracteriza-se pela interação e pelo fato de não ser mecânica. Este fato leva de volta à discussão de Freire (1987), na medida em que, ao ser significativo, a aprendizagem não pode ser mecânica, ou funcionar como um repositório "bancário", devendo ser processual.

Pelizzari e outros (2002) advogam que Ausubel (1982) divide a aprendizagem em dois eixos, quais sejam: a aprendizagem memorística e a aprendizagem significativa. O primeiro eixo tem estreita ligação com uma visão mecânica da aprendizagem. Pelizzari et al. (2002, p.39) afirmam que:

[...] quanto mais se relaciona o novo conteúdo de maneira substancial e não arbitrária com algum aspecto da estrutura cognitiva prévia que lhe for relevante, mais próximo se está da aprendizagem significativa. Quanto menos se estabelece esse tipo de relação, mais próxima se está da aprendizagem mecânica ou repetitiva.

Outro ponto importante no processo ensino-aprendizagem é a ideia de que o conhecimento não é atemporal, descontextualizado, dissociado da realidade da comunidade onde se realiza. Logo, é necessário que o 
processo seja permeado pelas circunstâncias que envolvem os indivíduos participantes do processo de aprendizagem. Assim sendo, reforça-se a percepção construída neste artigo de que o processo de aprendizagem é interativo, situado, contextualizado, processual, contra a ideia já superada de que não importa o processo de ensino, mas apenas seus resultados, e que estes independem dos elementos envolvidos.

Diante da visão de que o binômio "ensino-aprendizagem" se constitui em um verdadeiro processo, e que o contexto é uma variável relevante, atualmente o é importante pensar considerando as novas ferramentas e processos de ensino disponíveis e já em uso, como os recursos estéticos no ensino-aprendizagem em Administração (DAVEL et al., 2004). Fischer, Davel e Vergara (2006), discorrendo sobre o tema, afirmam que, no processo de aprendizagem, a prática está relacionada com experiências vividas e imaginárias, cognição e emoção, especialmente no ensino da Administração.

Vale ressaltar que ensinar administração é tão complexo e desafiador quanto ensinar outras áreas de ciências sociais que lidam com a dimensão humana em sua grandeza, vilanias e paixões. Em um campo complexo que tem o poder como conceito-chave, o aprendizado se dará pelo encontro com as teorias e pela compreensão das razões dos que exercem as práticas (FISCHER; DAVEL; VERGARA, 2006, p.I-2)

Esta visão reforça a teoria da aprendizagem significativa, em que o uso de subsunçores é fundamental. Subsunçores remetem a uma teorização desenvolvida por Ausubel (1982) para denominar a ancoragem de um novo conhecimento às estruturas cognitivas pré-existentes. No caso do ensino da Administração, como já foi destacado, é muito importante interligar a prática com a teoria para que se tenha significado na aprendizagem vivida pelo aluno. Caso contrário, corre-se o risco de que aconteça uma aprendizagem memorística e mecânica.

O ensino de Administração tornou-se foco de fortes debates acadêmicos nos últimos anos (AKTOUF, 2000; VERGARA; DAVEL; GHADIRI, 2007; BENNIS; o'TOOLE, 2005). Para Fischer (2005), que defende uma ampla reformulação do ensino de Administração no Brasil, é imperativa a mudança da atual estrutura. Tal modificação incluiria a construção e experimentação de 
modelos de ensino; institucionalização de linhas de pesquisa sobre ensino e aprendizagem em Administração; produção de materiais e textos didáticos; estímulos a experimentações e inovações no ensino presencial e à distância (FISCHER, 2005).

Neste sentido, a experiência aqui estudada representa uma experimentação que pode contribuir para aprimorar o processo de ensino e aprendizagem de Administração. Rechaçando a prática de uma aprendizagem mecânica e inovando o processo de ensino ao incorporar elementos mais dinâmicos, a experiência aqui analisada pode contribuir para a reflexão nesta rica seara de debates. 


\section{METODOLOGIA DA PESQUISA APLICADA}

A pesquisa caracteriza-se por ser um survey de natureza descritiva, com base na classificação de Gil (1999), sem pretensão de generalização. A principal variável investigada foi a Avaliação Geral da Disciplina. O questionário era composto por dez questões (sete objetivas e três discursivas). As questões objetivas foram submetidas a tratamento estatístico, enquanto as discursivas foram tratadas por meio da técnica DSC (Discurso do Sujeito Coletivo).

O Dsc é uma proposta para organização e tabulação de dados qualitativos fazendo a junção de vários discursos de um grupo de sujeitos, a fim de se criar um pensamento coletivo. A técnica é recente, surgiu na Universidade de São Paulo e vem obtendo visibilidade nas mais variadas áreas de pesquisa. Consiste basicamente em: I) selecionar o essencial do conteúdo de cada depoimento; 2) associar estes conteúdos a uma descrição de sentidos; 3) agrupar os depoimentos em categorias; 4) reunir os depoimentos de uma mesma categoria em um discurso único redigido na primeira pessoa do singular (LEFEVRE; LEFEVRE, 2006). Os principais pesquisadores desta técnica no Brasil são Fernando Lefevre e Ana Maria Cavalcanti Lefevre. O Dsc busca criar um "eu ampliado", pois, apesar de dois ou mais sujeitos compartilharem uma mesma ideia, eles respondem de forma distinta uma mesma pergunta. A técnica tenta reconstruir um sujeito coletivo vinculando um discurso ao conteúdo ampliado, sempre na primeira pessoa, representando a pessoa coletiva. (LEFEVRE; LEFEVRE, 2006).

Assim, foi solicitada aos alunos a avaliação dos seguintes componentes do processo: as aulas-conferência ministradas no auditório, as aulas-monitoria conduzidas pelos monitores, palestras realizadas e, por fim, uma avaliação geral da disciplina. Nas questões objetivas, os respondentes deveriam indicar sua opinião por meio de uma escala de cinco níveis (péssimo, ruim, regular, bom, ótimo).

Após a tabulação, os dados receberam tratamento estatístico para a realização das análises quantitativas.

Foram aplicados iıg questionários (quantidade de alunos regularmente matriculados na disciplina "Introdução à Administração") durante uma 
das últimas aulas-conferência. Foram obtidos 72 questionários respondidos, o que corresponde a $60,5 \%$ da população, podendo ser considerada uma amostra representativa do universo investigado. A amostra então ficou assim composta por curso: 2I estudantes de engenharias, 25 de nutrição, I6 de arquivologia, 2 de economia, 6 de direito, I de computação e um de estatística. Em função desse aspecto, não foram feitas discussões sobre os resultados dos alunos dos cursos de economia, computação e estatística, uma vez que a participação deles é muito pequena.

Vale observar que, tendo sido o questionário aplicado nos últimos dias de aula, constata-se nesse período um esvaziamento normal por conta de alunos que já estão aprovados na disciplina e preocupados e voltados para outras disciplinas ainda em encerramento. O questionário não foi aplicado antes porque a trajetória da disciplina ainda não estava completa.

Além da percepção dos discentes, foi analisada a percepção dos docentes envolvidos neste estudo. Trata-se de um grupo de discentes composto por um professor titular da Universidade, onde o curso é oferecido, e quatro alunos do curso de mestrado e doutorado em Administração da mesma escola. A percepção dos docentes foi coletada por meio de uma descrição densa que cada um foi solicitado a apresentar em torno de sua percepção sobre a experiência e sobre os resultados do processo de aprendizagem apresentado pelos discentes.

Após a coleta das informações, foi feita a análise de conteúdo do relato dos docentes, buscando-se identificar os aspectos mais importantes em suas descrições. As similaridades dos discursos dos docentes são apresentadas no tópico: Percepção docente. Os resultados obtidos são apresentados e discutidos nas seções seguintes. 


\section{A EXPERIÊNCIA: HISTÓRICO E DESCRIÇÃO DAS ATIVIDADES}

A disciplina "Introdução à Administração" faz parte da grade curricular obrigatória de diversos cursos de graduação na Universidade estudada, o que gera uma demanda permanente para a Escola de Administração. Para melhor atender a esse quadro, iniciou-se em 2006 o Projeto Experimental, em que os alunos provenientes de outros cursos de graduação como Direito, Nutrição, Engenharia, Arquivologia, Secretariado, entre outros, são reunidos semestralmente em uma turma formada por Ioo a I20 alunos. As aulas são ministradas pelo professor responsável pela disciplina com o auxílio de monitores, alunos do mestrado e doutorado do Programa de Pós-graduação.

O plano didático da disciplina é então conduzido da seguinte forma: a cada semana são realizados dois encontros. O primeiro será aqui chamado de aula-conferência, realizado no auditório para a turma completa. No encontro seguinte, a turma é dividida em grupos menores, com média de 30 alunos cada, conduzidos pelos monitores, o que serão chamados de aulas-monitoria. Os monitores acompanham todas as aulas-conferência ministradas pelo professor responsável.

O programa da disciplina é definido pelo professor. Em termos de conteúdo e estratégias didáticas, as aulas-monitoria são definidas em conjunto pelo professor e pelos monitores. Entende-se que, enquanto o objetivo da aula-conferência é abordar aspectos mais teóricos do conteúdo, as aulas ministradas pelos monitores têm como objetivo detalhar o assunto trabalhado no grande grupo com um foco mais aplicado, trazendo exemplos práticos, por meio de exercícios em sala e dinâmicas, abrindo-se um espaço favorável à criatividade, interatividade e experimentação.

A cada semestre, o professor responsável permanece, mas um novo grupo de monitores faz parte do projeto. O novo grupo de monitores comunicase com os monitores do semestre anterior para trocar ideias, no sentido de aproveitar o que foi bem sucedido e superar os pontos considerados insatisfatórios. O novo grupo tem ainda a oportunidade de implantar novas ideias e sugestões. 
Com relação ao conteúdo da disciplina, o objetivo é introduzir os alunos na diversidade teórica das Escolas de Administração e agregar conhecimento sobre as áreas funcionais, de modo que o discente possa ter um conhecimento geral sobre as distintas teorias da área. A escolha dessa abordagem, bem generalista, deve-se à diversidade dos cursos de origem dos alunos.

Nessa linha de ofertar um conteúdo de caráter mais amplo e diversificado, além das aulas-conferência e das aulas-monitoria, são realizadas também palestras por profissionais atuantes na gestão, formados ou não em Administração, o que funciona também como uma estratégia auxiliar, a fim de despertar maior interesse entre os alunos. Os palestrantes são escolhidos em diversas áreas de atuação, com a proposta de relatar para a turma, baseados em suas experiências profissionais, como se dá a gestão em seus respectivos campos. Como maneira de incentivar a participação dos alunos, são solicitados relatórios individuais sobre cada palestra, onde eles devem evidenciar sua compreensão sobre a temática abordada pelos convidados, bem como estabelecer uma relação entre as escolas teóricas estudadas durante as aulas e as experiências relatadas pelos profissionais gestores.

A avaliação da disciplina é constituída por quatro critérios: duas provas, as notas dos relatórios das palestras e uma nota proveniente dos trabalhos realizados nas aulas-monitoria. As provas constam, geralmente, de três questões discursivas e três objetivas e são realizadas em grupo de quatro estudantes. Essa dinâmica de avaliação tem como pressuposto que o trabalho na área de Administração é fundamentalmente em grupo.

Vale salientar que tanto a elaboração quanto a correção da avaliação aplicada aos alunos são coordenadas pelo professor, ouvindo-se os monitores sobre as experiências em cada microgrupo, a fim de contemplar as especificidades de cada turma. 


\section{CARACTERIZAÇÃO DA TURMA 2008.2}

É importante, agora, destacar as características específicas da turma 2008.2, da qual trata este artigo. A turma 2008.2 teve a disciplina "Introdução à Administração" ministrada pelo professor $\mathrm{P}$, acompanhado pelos monitores I, J, K e L, tendo sido composta por II9 alunos. Os alunos foram divididos em quatro grupos menores. O critério adotado para divisão das turmas foi o de ordem alfabética, não uma divisão geral por curso de origem dos alunos, visando, pela aleatoriedade, produzir uma combinação de diversidade dos cursos de origens dos participantes das turmas, havendo assim, uma intenção deliberada de misturar os alunos vindos dos diferenciados cursos.

Do mesmo modo foram definidos os critérios de avaliação. Para evitar grandes distorções entre as avaliações de um monitor para outro, elas foram elaboradas conjuntamente, buscando-se contemplar questões que englobassem assuntos explorados nas quatro turmas das aulas-monitoria. Posteriormente, eram promovidos também encontros com o professor, a fim de se definir os critérios de avaliação.

Ao longo do semestre da turma 2008.2 foram realizadas três palestras. A primeira palestrante foi uma nutricionista, que abordou o tema "A atuação do nutricionista no campo da Administração", seguida por uma Engenheira Civil, que proferiu a palestra "Construção Civil: um desafio para a Administração?” e, por fim, uma psicóloga que proferiu a palestra intitulada "Tendências em Gestão de Pessoas".

Além disso, uma estratégia utilizada na turma foi a criação de uma página na Internet onde foram disponibilizados os slides utilizados pelos monitores, vídeos, textos estudados em sala e as apresentações das palestrantes. Os alunos tinham acesso irrestrito à página, podendo, inclusive, deixar recados, tirar dúvidas ou contribuir com alguma experiência ou indicação de algum material que pudesse contribuir para a dinâmica das aulas. 


\section{RESULTADOS E DISCUSSÕES}

Dada a natureza das questões aplicadas (fechadas e abertas), a percepção dos discentes será apresentada em dois tópicos distintos: em um primeiro momento serão tratadas as questões objetivas, com viés mais quantitativo, em seguida serão apresentadas as percepções captadas pelo viés qualitativo, por meio de questões discursivas que foram tratadas por meio do discurso do sujeito coletivo (DSC). 


\section{A PERCEPÇÃO DISCENTE - ABORDAGEM QUANTITATIVA}

A seguir são apresentadas análises das percepções dos alunos, por curso, sobre a dinâmica da disciplina, contemplando diversos aspectos didáticos e como o processo contribuiu para a formação de cada um. A primeira questão é mostrada no Gráfico I.

Gráfico 1 Avaliação Percentual das Aulas-Conferência

Questão Qual a sua avaliação das aulas ministradas pelo professor P no auditório?

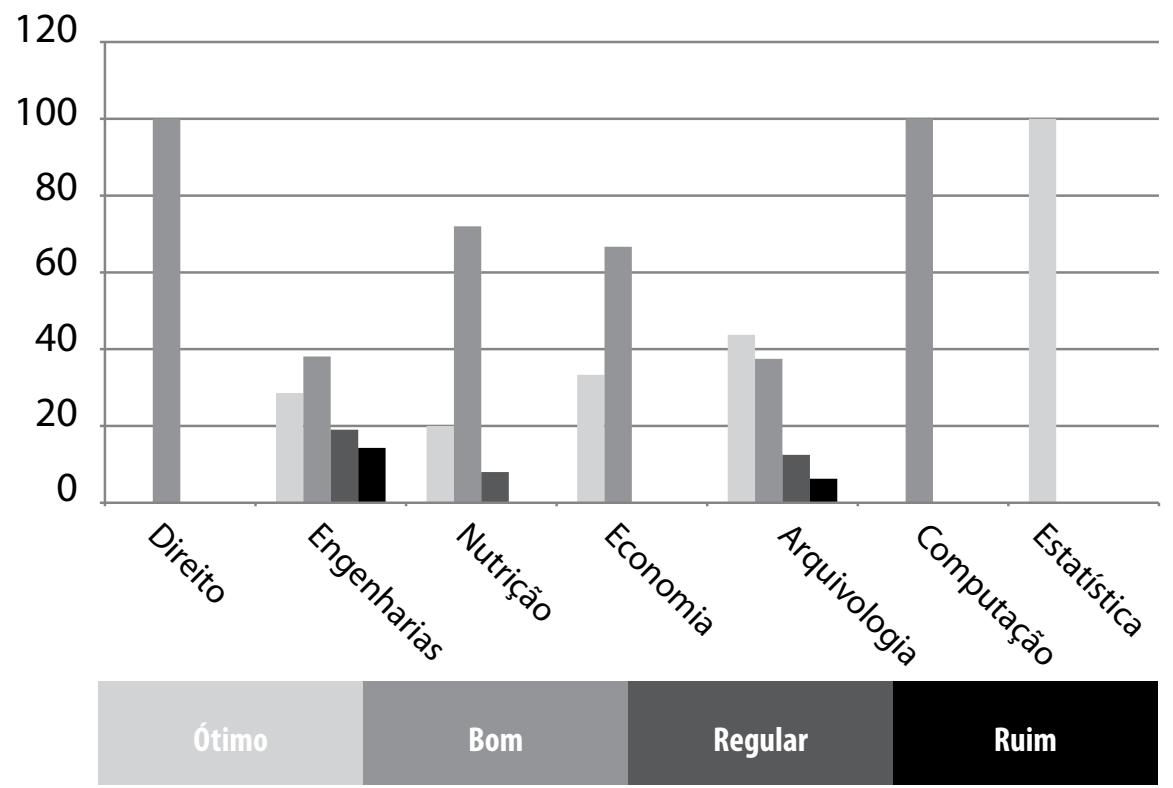

Os alunos dos cursos de Engenharia e Arquivologia tendem a avaliar que as aulas-conferência apresentam menor qualidade do que os alunos dos demais cursos. Alunos do curso de Engenharia tendem a uma dispersão maior. Realizadas no auditório para um grande número de estudantes, as aulas-conferência não permitem interações substanciais entre professor e alunos, diferentemente do que ocorre nas aulas realizadas pelos monitores.

Outro aspecto importante a observar é a diferença das respostas em 
função do curso a que pertencem os alunos. Os alunos de Nutrição tendem a avaliar mais positivamente as aulas-conferência no auditório do que os alunos de Arquivologia e de Engenharia, por exemplo. No caso de Engenharia, é que aparece o maior percentual de alunos que avaliam esta questão com maior valor de "regular". Isso demonstra uma relação entre o curso a que pertencem os alunos e as notas atribuídas ao item avaliado. É importante mencionar ainda que os alunos de Engenharia, em contrapartida, e por conta da avaliação menos positiva, apontam as maiores necessidades de ajustes na forma de ministrar as aulas-conferência.

A questão a seguir avalia a percepção dos alunos quanto às aulas-monitoria, avaliando a contribuição destas no processo de ensino e, consequentemente, no processo de aprendizagem. Os resultados obtidos estão representados no Gráfico 2.

Gráfico 2 Avaliação Percentual das Aulas-Monitoria Questão Qual a sua avaliação das aulas ministradas pelos monitores em grupos menores?

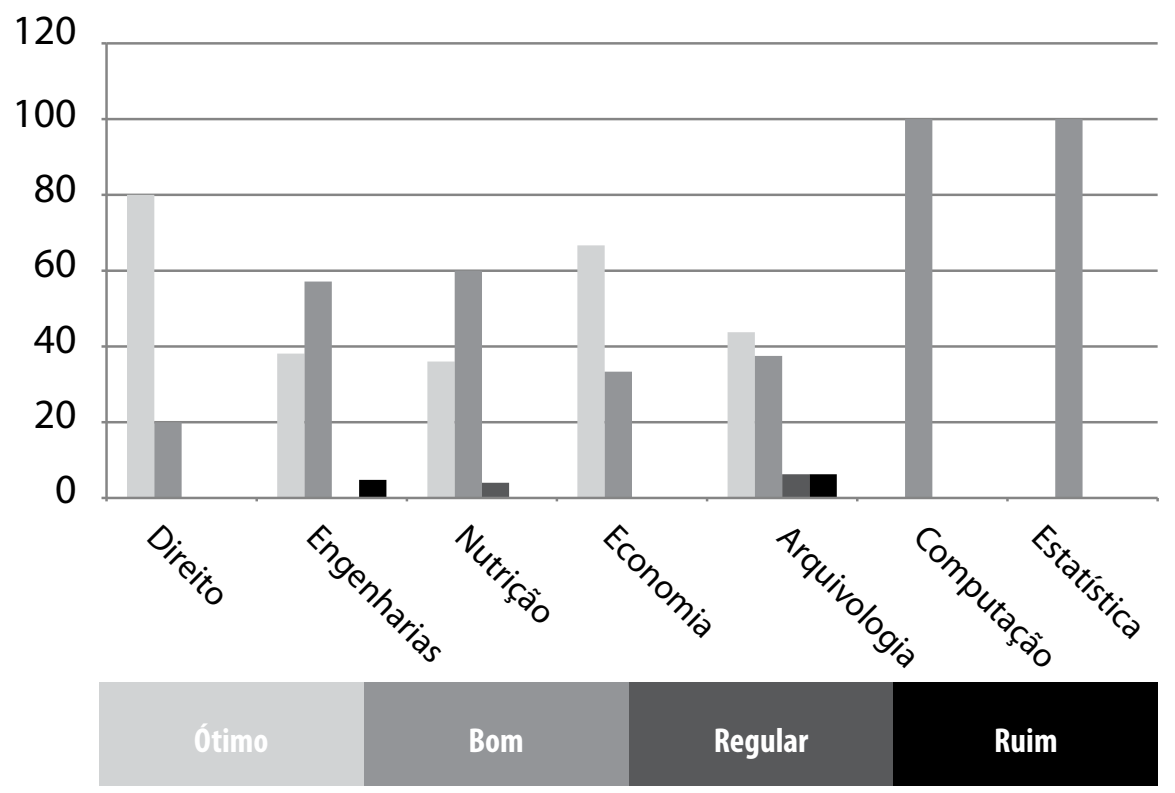


É possível observar um alto nível de satisfação com as aulas ministradas pelos monitores. Pode-se supor que essa melhor avaliação esteja associada à grande interatividade, possibilitada pela dinâmica dessas aulas. Nos grupos menores, as aulas são mais direcionadas à aplicação dos conceitos, à dinâmica, aos trabalhos em grupos e permite a participação dos alunos de forma mais intensa, em função dos recursos utilizados (DAVEL et al., 2004; FISCHER; DAVEL; VERGARA, 2006). Essa possibilidade está também alinhada com o conceito da aprendizagem significativa na dimensão da integração abordada anteriormente (MOREIRA, 1999). A redução do tamanho da turma permite também aos monitores não só conhecer melhor os alunos como avaliar mais adequadamente as possibilidades e potencialidades dos alunos, principalmente em termos de compreensão da disciplina, tanto individual quanto coletivamente. Isso permite, inclusive, avaliar como os distintos grupos presentes (Engenharia, Direito, Arquivologia, Nutrição) percebem e assimilam os conceitos apresentados. Ressalta-se que a não menção dos alunos dos demais cursos (estatística, computação e economia) deveu-se ao fato da baixa participação destes no total da amostra, fato que se repete nos gráficos 2, 3 e 4, seguintes.

Nesta questão, não há diferença significativa das percepções dos alunos em função dos seus cursos de origem - avaliações positivas ficaram para os cursos com maior número de alunos destacados, com 90\% de "bom" e "ótimo" para Engenharia, 93,33\% para Arquivologia e $96 \%$ para Nutrição, indicando uma avaliação positiva das aulas-monitoria.

Ao fazer a comparação com os resultados da questão anterior, é importante observar que, as aulas-conferência parecem ser menos bem avaliadas do que as aulas-monitoria. Pode-se supor que isso se deve à sua própria dinâmica, onde existe um distanciamento consciente entre o professor e os alunos e onde há uma carga mais explícita de teoria.

A questão seguinte avalia as palestras dos profissionais convidados por curso de origem dos alunos. Neste processo é mensurado como os alunos percebem a relação entre a disciplina e a prática de cada profissão, utilizando conceitos da Administração. O objetivo da disciplina neste aspecto é aproximar o conteúdo exposto em sala de aula com a visão 
prática dos profissionais que ministravam as palestras. Os dados constam do Gráfico 3.

Gráfico 3 Avaliação Percentual das Palestras

Questão Qual sua avaliação das palestras (Nutrição, Engenharia Civil, Gestão de Pessoas)?

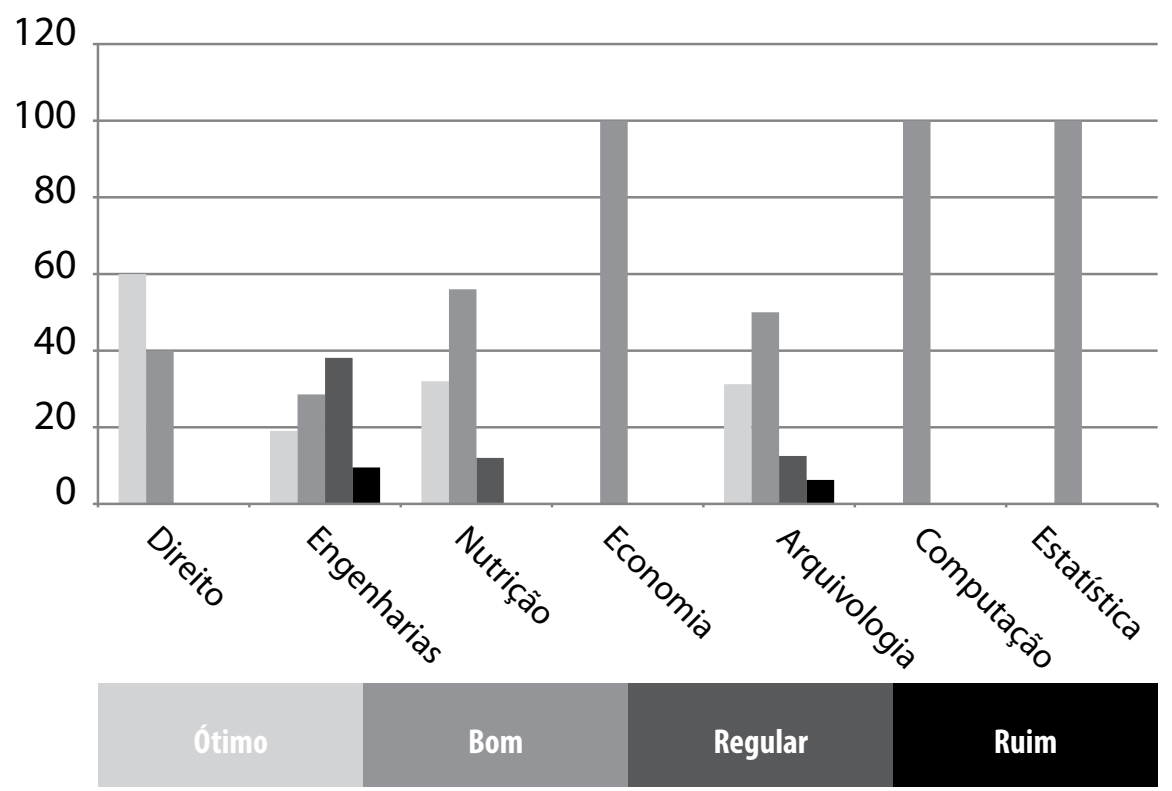

Nesse ponto, é importante esclarecer quais foram as motivações para a realização das palestras, que foram concebidas como forma de permitir uma aproximação dos alunos entre o mundo teórico da disciplina "Introdução a Administração" e o "mundo real" de suas profissões. O objetivo era mostrar como as diversas profissões se relacionam e utilizam conhecimentos de gestão em suas atividades diárias, visando mostrar como é o cotidiano profissional de um administrador e também chamar a atenção para o fato de que, ainda que não estejam se graduando como administradores, eles podem vir a atuar como gestores em suas vidas profissionais. As palestras 
tinham, então, o intuito de mostrar aos alunos que frequentar a disciplina "Introdução à Administração", apesar de esta não fazer parte do corpo principal de disciplinas técnicas de seus cursos de origem, não deveria ser vista como perda de tempo, uma vez que haverá um uso posterior, em suas vidas profissionais, dos conhecimentos adquiridos na disciplina.

A análise das respostas a esta questão permite identificar um nível de concordância menor do que nas questões anteriores. É interessante notar que, mesmo entre os estudantes de áreas afins às do palestrante, não houve, de modo geral, avaliações tão positivas para tais palestras. Mas, por outro lado, as avaliações também não foram negativas (antes de apurar os resultados, havia uma expectativa por parte dos docentes de que alunos de cursos não contemplados por palestras específicas de sua área ficassem menos satisfeitos do que os alunos de cursos contemplados). Entretanto, pode-se observar que, com exceção dos alunos de Direito, os estudantes apresentaram, em geral, níveis de satisfação razoáveis, com poucas respostas "ruim". Para os alunos de Nutrição, por exemplo, a soma de respostas "bom" e "ótimo" fica acima de $80 \%$.

Na próxima questão, é avaliada a percepção dos alunos sobre o nível geral de satisfação com a disciplina "Introdução à Administração". 
Gráfico 4 Avaliação Percentual Geral da Disciplina Questão Qual sua avaliação geral da disciplina de "Introdução à Administração"?

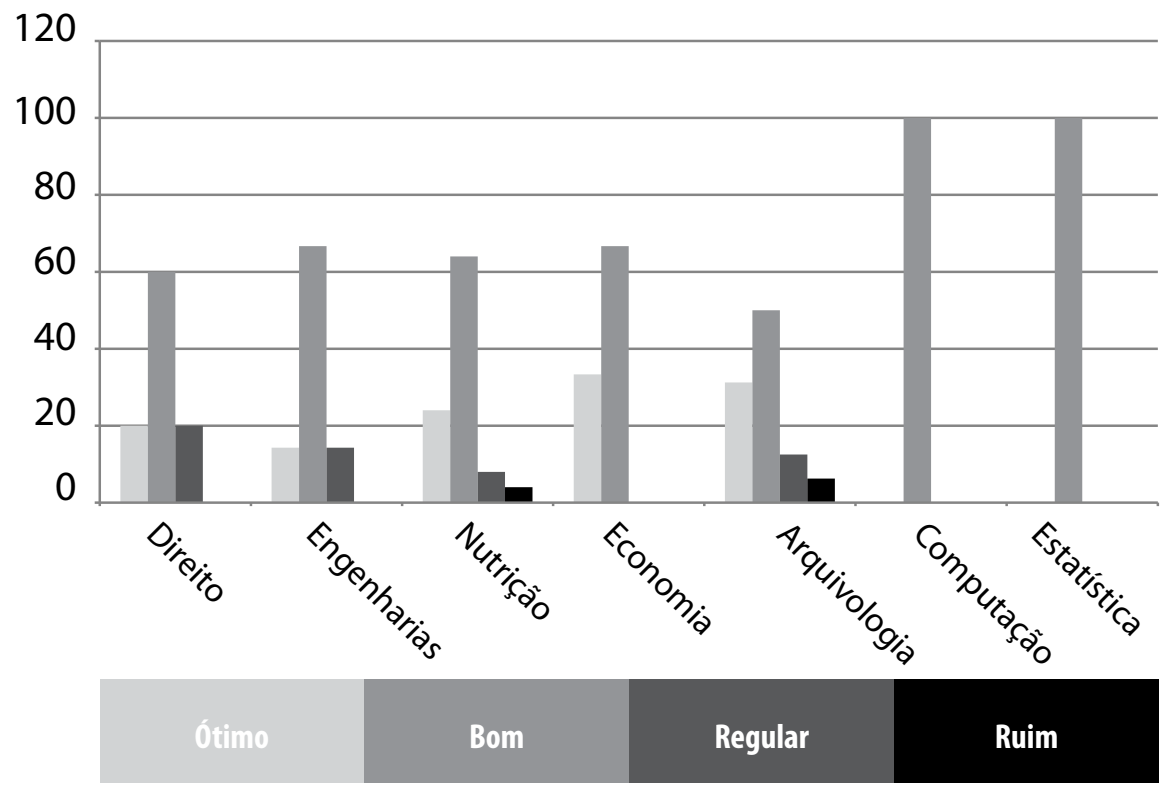

Como pode ser observado no Gráfico 4, embora o nível de avaliações se apresente com resultados positivos, há uma redução na satisfação dos alunos, em relação às questões anteriores. De todas as perguntas aplicadas, esta foi a que apresentou os mais baixos índices da opção "ótimo" na avaliação, embora a opção "bom" lidere sobejamente.

Nesse sentido, cabe então fazer algumas discussões sobre esta questão.

Em primeiro lugar, a disciplina é, de uma forma geral, bem avaliada pelos alunos de todos os cursos. Não há diferença significativa entre as percepções dos alunos de diferentes cursos. Além disso, quando estes números são comparados aos relatos dos estudantes, que serão apresentados na próxima sessão, percebe-se uma coerência entre os diversos discursos.

Em segundo lugar, há uma relação muito forte entre o grau de satisfação com a disciplina e as falas dos alunos sobre o que a mesma representa 
O PROCESSO ENSINO-APRENDIZAGEM EM ADMINISTRAÇÃO EM CONDIÇÕES DE HETEROGENEIDADE

para sua formação. Isto poderá ser verificado a seguir, quando analisadas as respostas dos discentes, ao serem questionados sobre a importância da disciplina para sua formação profissional. 


\section{A PERCEPÇÃO DISCENTE - ABORDAGEM QUALITATIVA}

Para a criação do Sujeito Coletivo, foram realizados os seguintes passos baseados em discursos coletados dos alunos: (I) Inicialmente foram selecionadas Expressões-Chave (E-Ch) de cada discurso (respostas à questão 9 do questionário de pesquisa). Cada expressão-chave, segmentos, contínuos ou descontínuos, de discurso, revela o cerne das respostas; (2) Em seguida, buscou-se a identificação da Ideia Central (Ic) de cada uma das expressõeschave selecionadas no passo anterior. Uma IC é a síntese do conteúdo das E-Ch; (3) Foram identificadas as ideias centrais semelhantes, por meio de códigos de uma categorização (por exemplo, IC-A, IC-B, etc); (4) As expressões-chave ligadas às ideias centrais foram reunidas em um discurso síntese que é o discurso do sujeito coletivo (DSC).

O Dsc foi aplicado nesta pesquisa para a questão que indagava sobre o formato das aulas da disciplina (Questão 9 - Qual sua opinião sobre o formato das aulas?), ou seja, aulas-conferência e aulas-monitoria. Um primeiro extrato quantitativo sobre a frequência de Ideias Centrais pode ser observado na Tabela I.

Tabela1 Frequência de Ideias Centrais

\begin{tabular}{|lll|}
\hline Código IC & Descrição da IC & Freq. IC \\
\hline IC - A & O formato favorece o aprendizado. & $34 \%$ \\
\hline IC - B & O formato é improdutivo, principalmente as aulas no auditório & $10 \%$ \\
\hline IC - C & O formato é inadequado, o assunto é tratado com superficialidade. & $4 \%$ \\
\hline IC - D & O formato possibilita a comparação entre teoria e prática. & $13 \%$ \\
\hline IC - E & O formato possibilita a integração, a participação e o debate. & $38 \%$ \\
\hline
\end{tabular}

O discurso mais representativo, IC-E, afirma que o formato favorece a integração e participação dos alunos, como pode ser observado no Quadro I. É interessante destacar que a variedade de recursos didáticos foi percebida como algo positivo. É oportuno observar que ao IC-E se segue, de perto, o IC-A, ou seja, os alunos reconhecem que o formato adotado favorece o 
aprendizado. Vale destacar que a participação nas aulas-conferência foi reconhecida como algo inviável.

Quadro1 Discurso do Sujeito Coletivo da IC-E

\section{IC - E [O formato possibilita a integração, a participação e o debate]}

O contato com outras áreas conferiu diversidade às aulas de monitoria, o que possibilitou o compartilhamento de experiências. A participação que era inviável nas aulas de auditório acontecia com mais frequência nas aulas-monitoria, onde os alunos eram mais assistidos, os encontros mais dinâmicos e as dúvidas perfeitamente sanadas.

O Quadro 2 detalha o discurso IC-A, que destaca o dinamismo das aulasmonitoria. Isso demonstra que os debates e o espaço de participação criados nessas aulas favoreceram a aprendizagem dos alunos (WEICK; WESTLEY, 2004). Nos debates, cada estudante faz uso dos subsunçores (MOREIRA, 1999) que possui, para fundamentar seus argumentos. Quando isso é somado à grande pluralidade de formações, possivelmente tem-se uma condição mais propícia para a aprendizagem.

Quadro2 Discurso do Sujeito Coletivo da IC-A

\section{IC - A [O formato favorece o aprendizado]}

O formato adotado favorece a aprendizagem já que o conteúdo abordado no auditório era esmiuçado nas aulas de monitoria. Isso facilitou o rendimento do conteúdo e o aproveitamento das informações, pois o estudante fica mais próximo do professor/monitor. As aulas em pequenos grupos eram mais dinâmicas e reforçavam o que fora debatido no auditório.

O discurso IC-D, que pode ser observado no Quadro 3, destaca a ligação entre teoria e prática proporcionada por este formato. $\mathrm{O}$ uso de diversos recursos didáticos (vídeos, estudos de caso, etc.) faz com que as aulasmonitoria sejam um contraponto com viés mais prático às aulas-conferência. Isto também é destacado pelo discurso dos alunos como algo positivo, reforçando a importância da inserção de novas alternativas e métodos no processo de ensino-aprendizagem, conforme destacam Davel et al. (2004) e Vergara et al. (2007). 


\section{Quadro3 Discurso do Sujeito Coletivo da IC-D}

\section{IC - D [O formato possibilita a comparação entre teoria e prática]}

As aulas ministradas no auditório apresentam abordagens mais gerais e panorâmicas sobre a teoria administrativa. Já as aulas nos grupos menores intensificam os aspectos práticos dos conteúdos debatidos no auditório por meio de cases, vídeos etc. É possível realizar um paralelo muito interessante entre teoria e prática deste modo.

Conforme mencionado anteriormente, participaram desta experiência, além do docente titular da disciplina, quatro monitores, alunos de mestrado e doutorado em Administração da Universidade Federal em estudo. A seguir serão apresentados os principais elementos dos relatos do Professor P e dos quatro monitores (designados pelas letras I, J, K e L) da turma 2008.2, destacando suas percepções, conflitos e fatos marcantes vivenciados no processo. 


\section{PERCEPÇÃO DOS DOCENTES}

A principal característica da experiência que os docentes destacam é a grande heterogeneidade que permeia toda a experiência. Com forte presença nos relatos, essa natureza heterogênea pode ser observada tanto em relação aos discentes (diferentes cursos de origem, idade, período em que estão na faculdade) quanto aos próprios docentes (diferentes formações, níveis de experiência didática, etc). Nesse contexto, a heterogeneidade é o elemento da experiência que, se por um lado confere ao processo uma gama ampla de desafios, por outro lado se constitui também em rica potencialidade para superá-los.

Nesse sentido, entre desafios e oportunidades de ensinar em condições de alta heterogeneidade, os docentes destacaram, entre outros:

Fazer com que alunos de cursos tão diversos estabeleçam relação entre a Administração e suas próprias áreas de conhecimento - A grande dificuldade, nesse caso, está em fazer com que os alunos percebam na Administração uma relação com sua atuação profissional, vendo inclusive possibilidades futuras de inserção no mercado, no campo da gestão, em suas respectivas áreas. Nesse sentido, já a definição do conteúdo da disciplina é desafiadora. Dessa forma, a introdução de palestras com profissionais gestores em áreas afins às dos estudantes matriculados na disciplina teve como objetivo reforçar a relação entre o conteúdo de Administração abordado durante a disciplina e as diversas áreas das quais os alunos se originam.

Flexibilidade para trabalhar com a disparidade entre o nivel de conhecimento dos alunos dos diferentes cursos - A diferença entre o nível de conhecimento dos alunos que existe numa turma regular é muito acentuada nas turmas investigadas neste estudo. Os diferentes cursos de origem dos alunos implicam grande desigualdade na formação educacional dos mesmos (devido à disparidade na renda familiar e diferentes competências trabalhadas. Essa disparidade reflete-se diretamente na postura dos alunos nas aulas: os formandos de Direito apresentavam maior capacidade de argumentação (inerente, talvez, à sua formação), enquanto os alunos de Arquivologia (que tendem a um perfil de baixa renda familiar) relutavam em participar 
dos debates promovidos em sala, visivelmente intimidados pela diferença de capacidade discursiva que tinham em relação ao restante da turma, o que ficava latente em sua postura tímida e voz baixa. Essa disparidade então exigiu, em ocasiões como a correção das avaliações, que os docentes adotassem uma postura flexível, policiando-se constantemente para não se ater somente às notas dos alunos de Direito - que apresentavam pontuações mais altas - como parâmetro para a correção das provas de alunos de Arquivologia, por exemplo.

Enriquecimento dos debates em sala devido à diversidade de visões de mundo dos alunos de diferentes cursos - A heterogeneidade possibilita também intensa troca de experiências. Neste sentido, as discussões ganham contornos bastante diferentes do que ocorrem com as turmas formadas por alunos de apenas um curso. Como exemplo, a ocasião relatada pelo monitor J em que, depois de ter sido apresentado um vídeo em que se criticava o modelo taylorista, debatia-se esse modelo de administração, comparando-o com a contemporaneidade:

Inicialmente, um aluno de Engenharia disse que o modelo taylorista era atual, necessário e praticado ainda nos dias de hoje. Percebi a expressão de espanto de alguns. Outro aluno de Engenharia corroborou a opinião, indo além: defendeu que "os objetivos da empresa devem estar acima de tudo e devemos deixar de lado o 'romantismo', pois sabemos muito bem que é assim que as coisas funcionam". Esta opinião aqueceu o debate. Um aluno de Economia reagiu indignado, afirmando que o empregador apenas explorava as pessoas e que os trabalhadores não deveriam se "submeter" aos maus tratos impostos pelo "sistema capitalista". Os alunos de Engenharia contra-argumentavam. O economista, sozinho, resistia, quando um estudante de Direito tomou parte do debate. Segundo ele, a relação empregador/empregado deveria ser observada pela ótica da legislação trabalhista, citando situações de assédio moral, cláusulas da CLT e outras legislações, tentando demonstrar como a teoria taylorista deveria ser enquadrada sob sua ótica. Alguns alunos me cercaram, questionando qual das visões era a correta. Tentei mostrar que as diferentes visões expostas não se encaixavam simplesmente nos rótulos de certo e errado e que, ao tomarmos consciência de diferentes visões sobre um 
mesmo tema, podemos compará-las com a nossa própria visão, inserida em um contexto, específico. Quando conhecemos visões diferentes das nossas, podemos nos questionar e tomar uma postura mais crítica sobre nossas ações. Os alunos estavam tão acostumados com o formato "bancário" de ensino e ao mesmo tempo tão fascinantemente desconfortável com aquela situação de confronto de ideias, que fiz várias vezes debates neste formato. Ao final da monitoria, alguns alunos me disseram que a experiência foi muito rica, pois não tinham oportunidade de debates daquela natureza em seus cursos. Intenso aprendizado docente - Também para os docentes a experiência possibilitou intenso aprendizado. Os monitores beneficiaram-se da rica troca de conhecimentos que acontece quando cinco docentes, com formação diversa, se reúnem para planejar a melhor abordagem para determinado conteúdo, o recurso estético mais adequado, ou para comparar, depois das aulas, o resultado das ações nas diferentes turmas (o que funcionou bem, o que precisa ser revisto, as diferenças de resultado em função do perfil de cada turma e de cada monitor, etc.). Além disso, o professor P esclarece que o novo grupo de monitores formado a cada semestre "não sai do zero", mas é beneficiado com a experiência dos monitores do semestre anterior.

Sob a perspectiva da aprendizagem significativa, os relatos evidenciam como os alunos fazem uso de diferentes subsunçores (conhecimentos prévios) para a assimilação do conhecimento no processo de aprendizagem. A constatação está alinhada com essa discussão à medida que os conhecimentos anteriores dos "engenheiros", por exemplo, permitiram interagir de maneira mais intensa com temas ligados aos princípios da própria formação. 


\section{CONSIDERAÇÕES FINAIS E LIMITAÇÕES DO ESTUDO}

Este trabalho buscou descrever e investigar uma experiência de ensinoaprendizagem da disciplina "Introdução à Administração" para alunos não administradores.

Estabelecendo relações entre os resultados da pesquisa e a abordagem teórica adotada, algumas considerações merecem ser assinaladas. A primeira delas diz respeito à noção de ensino-aprendizagem como processo e não como estímulo para um dado resultado (WEICK; WESTLEY, 2004). O trabalho de monitoria desenvolvido ao longo do semestre constituiu-se em permanente construção por meio do acompanhamento pelo professor responsável das atividades realizadas pelos monitores nas aulas-monitoria. O objetivo era conferir coerência entre as dinâmicas das quatro turmas, a fim de evitar grandes distorções entre elas. Do mesmo modo, o próprio esforço em envolver os alunos nas discussões e atividades durante as aulasmonitoria partiu do pressuposto de construção da disciplina por meio da interação de todo o grupo (MOREIRA, I999; WEICK; WESTLET, 2004).

Um segundo ponto diz respeito ao uso de subsunçores, essenciais para o processo de ensino-aprendizagem, conforme anteriormente colocado. A combinação de aulas-conferência com estudantes em microgrupos constituiu uma importante estratégia de ensino baseada na ideia de aprendizagem significativa, onde os momentos em pequenos grupos buscavam estimular a ancoragem dos conhecimentos prévios dos alunos, com a carga teórica debatida na aula-conferência. Importante lembrar que, além da heterogeneidade em relação aos cursos de origem, havia a referida variedade de períodos em que os alunos estavam em seus cursos, havendo na turma tanto alunos de primeiro quanto do quinto semestre, que conviviam ainda com formandos, o que parece ter influenciado também o processo. Nesse contexto, parece condizente supor que alunos em níveis mais avançados da graduação carreguem um quadro referencial mais amplo, e, por conseguinte, tenham maiores condições de ativar subsunçores, favorecendo sua aprendizagem individual, e, consequentemente, interferindo mais nas abordagens em grupo (MOREIRA, 1999). 
Uma terceira questão, ainda relacionando a experiência estudada com o processo de ensino-aprendizagem, refere-se à noção de conhecimento não como algo atemporal, mas contextualizado. Pode-se remeter essa ideia às palestras realizadas, em que os estudantes tinham a oportunidade de verificar a aplicação da Administração em realidades profissionais específicas, próximas às realidades de alguns deles. Além disso, a própria dinâmica das aulas-monitoria buscava favorecer essa noção, abordando-se o quadro teórico da disciplina sempre por meio de casos próximos da vivência dos alunos, a fim de despertar maior interesse e promover maior interatividade, propiciando uma construção coletiva. Estas palestras buscaram ainda propiciar condições para que os alunos realizassem a ancoragem entre suas realidades (de estudo, pessoal e também profissional já que alguns realizavam estágio e trabalhavam), a fim de que fosse vivenciada uma aprendizagem significativa (AUSUBEL, 1982).

Da análise deste processo, fica a constatação da viabilidade de colocar em prática no processo de ensino-aprendizagem os conceitos inicialmente tratados no referencial teórico. Os alunos apresentavam maior interesse diante de discussões em sala mais fortemente ligadas a temas de suas áreas. Isso remete ao conceito de aprendizagem significativa, com suas dimensões de interação e subsunçores (MOREIRA, 1999). Quanto mais próximo de sua área de conhecimento, mais atrativo se torna o tema a ser discutido. Da mesma forma, os discentes, ao interagirem de forma intensa com os temas, reforçaram a necessidade de vencer o tradicional modelo de "educação bancária", já devidamente criticado por Freire (1987), fato que, inclusive, foi comentado por alguns alunos: "falta um processo mais interativo de ensino em nossas aulas, nos nossos cursos de origem".

Outro fator importante a destacar é que, ao buscar uma variação de recursos pedagógicos visando favorecer a aprendizagem pelos discentes, promove-se também um intenso aprendizado aos docentes envolvidos no processo. Os docentes são beneficiados, assim, pela troca de conhecimentos entre professores com diversas formações e nível de experiência pedagógica, caracterizando uma rica oportunidade de aperfeiçoamento didático para eles (FISCHER, 2005). 
Cabe destacar que o presente trabalho apresenta algumas limitações. Uma delas é quanto à possibilidade de generalização, pois, sendo a experiência circunscrita aos termos locais, não é possível generalizar as conclusões deste estudo. Outra limitação a ser destacada é que a pesquisa se focou na investigação de apenas uma turma, a de 2008.2, desse Projeto Experimental. Sugere-se, então, que, em pesquisas futuras, outras turmas da experiência sejam investigadas, a fim de possibilitar uma análise mais aprofundada dos resultados e uma avaliação processual do próprio Projeto Experimental.

Por fim, a experiência mostra-se rica em resultados e em processos, podendo servir de base para experimentos similares, por meio da atenção às possíveis falhas, bem como para aprimoramento de pontos positivamente explorados. Além disso, trata-se de um material a ser explorado em reflexões futuras sobre a necessidade de reformulação do ensino em Administração defendida por alguns autores. 


\section{REFERÊNCIAS}

AKTOUF, O. Administración y pedagogia. Medellín: Editora Universidad EAFIT, 2000.

AUSUBEL, D. P. A Aprendizagem Significativa: a teoria de David Ausubel.

São Paulo: Moraes, 1982.

AZENHA, M. G. Construtivismo - De Piaget a Emília Ferreiro. São Paulo: Ática. 2006.

BASTOS, A. V. B. Cognição nas Organizações de Trabalho. In: ZANELLI, J.C.;

ANDRADE, J.E.B.; BASTOS, A.V.B. (Org.). Psicologia, Organizações e Trabalho no Brasil. 1.ed. Porto Alegre: Artmed, 2004, p. 256-292.

BENNIS, W. G.; O’TOOLE, J. Como a escola de administração perdeu o rumo. Harvard Business Review, v.83, n.5, p. 96-104, 2005.

DAVEL, E.; VERGARA, S.; GHADIRI, S.; FISHER, T. Revitalizando a relação ensinoaprendizagem em administração por meio de recursos estéticos. In: ENCONTRO NACIONAL DOS PROGRAMAS DE PÓS-GRADUAÇÃO EM ADMINISTRAÇÃO, 28., 2004, Curitiba. Anais... Curitiba: Anpad, 2004.

FISCHER, T. M. D. Engenhos e Artes do Ofício de Ensinar: PCDA, um Programa Brasileiro. Organizações \& Sociedade, v.12, n.35, p. 183-193, 2005.

FISCHER, T.; DAVEL, E.; VERGARA, S. Razão e Sensibilidade no Ensino de Administração: a Literatura como Recurso Estético. In: ENCONTRO NACIONAL DOS PROGRAMAS DE PÓS-GRADUAÇÃO EM ADMINISTRAÇÃO, 30., 2006, Salvador. Anais... Salvador: Anpad, 2006.

FREIRE, P. Pedagogia do oprimido. Rio de Janeiro: Paz e Terra, 1987.

GIL, A. C. Métodos e técnicas de pesquisa social. 5. ed. São Paulo: Atlas, 1999.

GIL, A.C. Como elaborar projetos de pesquisa. 4.ed. São Paulo: Atlas, 2002.

LEFEVRE, F.; LEVEFRE, A. M. O sujeito coletivo que fala. Revista InterfaceComunicação, Saúde e Educação, v.10, n.20, p.517-24, 2006.

LEOPOLDINO, C.; ABREU, J. C. A.; SANTANA, A. E. S. A Percepção do Corpo Discente Sobre uma Experiência de Ensino-Aprendizagem em Administração: Uma Abordagem Quantitativa. Salvador: Mimeo, 2008.

MORAN, J.M. Aprendizagem significativa. 01/08/2008. Disponível em $<$ http://www.eca.usp.br/prof/moran/significativa.htm>. Acesso em: 12/08/2010.

MOREIRA, M. A. Aprendizagem Significativa. Brasília: Ed. UnB, 1999.

PELIZZARI, A.; KRIEGL, M.L.; BARON, M.P.; FINCK N.T.L.; DOROCINSKI, S.I. Teoria da Aprendizagem Significativa segundo Ausubel. Revista Psicologia, Educação e Cultura, v.2, n.1, p.37-42, 2002.

TONET, H. C.; PAZ, M. G. Um modelo para o Compartilhamento de Conhecimento no Trabalho. Revista de Administração Contemporânea, v. 10, n. 2, p. 75-94, 2006. 
VERGARA, S. C.; DAVEL, E.; GHADIRI, D. P. (Orgs.). Administração com arte: Experiências vividas de ensino-aprendizagem. São Paulo: Atlas, 2007.

WEICK, K. E.; WESTLEY, F. Aprendizagem organizacional: confirmando um oximoro. In: CLEGG, S. R.; HARDY, C.; NORD, W. R. (Orgs.). Handbook de Estudos Organizacionais: Ação e análise organizacionais. São Paulo: Atlas, 2004.

YONEMOTO, H. W. Proposta de integração entre ensino, aprendizagem, comunicação e virtualidade, 2004. 347 f. Tese (Doutorado em Engenharia de Produção) - Universidade Federal de Santa Catarina - Programa de Pós Graduação em Engenharia de Produção. 


\section{DADOS DOS AUTORES}

INGRID WINKLER ${ }^{\star}$ ingridw@uol.com.br

Mestre em Administração pela Universidade Federal da Bahia Instituição de vinculação: Universidade Federal da Bahia

Salvador/BA - Brasil

Áreas de interesse em pesquisa: Democracia Digital, e-Participação, Governo Eletrônico.

${ }^{\star}$ Endereço: Av. Reitor Miguel Calmon, $s / n$

Vale do Canela Salvador/BA 40110-903

JÚLIO CESAR ANDRADE DE ABREU julioabreu@vm.uff.br

Mestre em Administração pela Universidade Federal da Bahia

Instituição de vinculação: Universidade Federal Fluminense

Volta Redonda/RJ - Brasil

Áreas de interesse em pesquisa: Administração Pública, Ensino e pesquisa em administração, Participação democrática, Sociedade da Informação.

KÁTIA SANTOS DE MORAIS katiamoraiso1@gmail.com

Mestre em Administração pela Universidade Federal da Bahia

Instituição de vinculação: Universidade do Estado da Bahia

Salvador/BA - Brasil

Áreas de interesse em pesquisa: Democracia digital,

Comunicação e Desenvolvimento Local, Mídias e Participação Política.

LINDOMAR PINTO DA SILVA lpsilva@sefaz.ba.gov.br

Doutor em Administração pela Universidade Federal da Bahia

Instituição de vinculação: Faculdade Anísio Teixeira

Feira de Santana/BA - Brasil

Áreas de interesse em pesquisa: Administração Pública, Cultura Organizacional, Gestão de Pessoas, Modernização Organizacional, Reforma do Estado, Ensino e Pesquisa em Administração.

JOSÉ ANTONIO GOMES DE PINHO jagp@ufba.br

$\mathrm{PhD}$ em Planejamento Regional pela University of London - LSE

Instituição de vinculação: Universidade Federal da Bahia

Salvador/BA - Brasil

Áreas de interesse em pesquisa: Ensino, Sociedade da Informação, Internet,

Democracia, accountability. 